\title{
Impôsto de Transmissão Inter Vivos e as Construções em Terreno Alheio
}

\section{Amilcar de ARaújo FALCÃo}

$336.2: 347.662: 711.60$

I NEGÀVelmente é o impôsto sôbre a transmissão da propriedade imobiliária inter vivos um daqueles que, no sistema brasileiro, maior número de problemas de ordem constitucional tem oferecido.

Está dentro dêsse teor de idéias a dúvida que vem sendo levantada, no sentido de saber se o impôsto em causa incide sôbre a entrega de imóveis construídos, feita pelos construtores aos proprietários da edificação.

O caso surgiu no Distrito Federal.

E' que se tem pretendido, com fundamento no inciso IV do art. $10^{\circ}$ do Decreto-lei n. ${ }^{0}$ 9.626, de 22 de agôsto de 1946, vigorante na esfera local, exigir o pagamento do impôsto de transmissão de propriedade inter vivos, por considerá-1o incidente sôbre a operação mencionada.

Êsse é o problema para o qual se procura a solução adequada: saber se a entrega de obras ou imóveis construídos por fôrça de contrato de empreitada enseja o fato gerador do impôsto indicado, em face da legislação fiscal vigente no Distrito Federal.

2. O ponto nuclear da questão está em definir-se o sentido da disposição contida no inciso IV do art. $10^{\circ}$ do Decreto-lei n. ${ }^{\circ} 9.626$, que assim soa:

"Art. $10^{\circ}$ - $\mathrm{O}$ impôsto de transmissão de propriedade inter vivos incide sôbre a transferência. de bens imóveis por sua natureza ou por definição legal, quando situados no Distrito Federal, a título oneroso ou gratuito, e em virtude de fatos ou atos jurídicos passados ou praticados inter vivos:

Parágrafo único - O impôsto é devido sôbre: .............. ...................................... (ommissis).

IV - transferência de construções existentes em terrenos alheios ainda que aos proprietários dos terrenos".

Para a devida fixação do alcance dêsse preceito, é conveniente determinar o fato gerador do impôsto de transmissão:

a) em face dos princípios acolhidos pela sistemát ca da discriminação constitucional de rendas; 
b) em face do próprio sistema seguido pela lei específica acima citada.

3. Vigora no Brasil uma discriminação rígida de rendas, de acôrdo com a qual a cada uma das entidades federadas (União, Estados e Municípios) é atribuída a competência legislativa para decretar certos e determinados impostos, devidamente identificados pela alusão ao fato gerador de sua incidência.

Doutrina e jurisprudência são pacíficas ao concluir que a enunciação feita no diploma constitucional não é simplesmente nominalista, isto é, não se trata de mera indicação de nomines jutis quando é feita referência a cada um dos tributos discriminados, mas, ao contrário, a menção é feita a impostos especificamente definidos de acôrdo com as características jurídicas que thes atribuem os fatos geradores apontados pelo legislador constituinte.

Essa maneira de entender as coisas, que, por sinal, é uniforme (ressalvase o ponto de vista particular de CARLOS DA Rocha GuIMARÃES), leva a duas conclusões importantes, pela incidência que terão sôbre o problema em cogitação:

a) na utilização da cédula de competência privativa, cada uma das entidades federadas há de proceder de tal forma que a fixação das hipóteses de incidência tributária não importe em distorção ou deformação dos fatos geradores constitucionalmente indicados como pressupostos para o exercício da competência impositiva;

b) pode ocorrer que, embora extravasando da cédula privativa, por distorção ou alteração do seu fato gerador típico, o impôsto instituído possa legitimar-se, como de competência concorrente (art. 21 da Constituição). Para tanto será necessário: $1^{\circ}{ }^{\circ}$ ) que o seu fato gerador seja inconfundível com aquêles indicados para o exercício da competência impositiva privativa; $2 .^{\circ}$ ) que especialmente, não se compreenda êle dentro da competência privativa ampla da União para tributar "atos e instrumentos regulados por lei federal" (art. 15, VI, da Constituição).

4. Diante dêsses princípios, como há de determinar-se a extensão e o alcance da competência legislativa atribuída aos Estados pelo art. 19, III, da Constituição para decretar impôsto sôbre a "transmissão de propriedade imobiliária inter vivos"?

Se, porventura, o legislador estadual extravasar de tal cédula e tributar situações que se exteriorizem ou sob forma jurídica que não traduza uma transmissão de propriedade, ou que, embora ensejando dita transmissão, não se refira à propriedade imobiliária, o impôsto assim instituído deixará de legitimar-se, dentro da competência privativa, como impôsto de transmissão de propriedade imobiliária inter vivos.

Restarão duas possibilidades: ou o impôsto de tal forma criado se identificará com algum dentre os de competência das demais entidades federadas e, portanto, será inconstitucional por invasão de competência, ou então o seu fato gerador será inconfundível com os demais constitucionalmente discrimi- 
nados, e o impôsto convalescerá como remanescente ou de competência concorrente.

5. Assim sendo, temos que, em face da sistemática adotada pelo legislador constituinte, o impôsto de transmissão da propriedade imobiliária inter vivos só poderá ser legitimamente exigido quando a sua incidência se verifique tendo em vista uma situação conceituável jurìdicamente como de transmissão ou transferênc'a inter vivos.

A transferência da propriedade é requisito elementar para tal tipo de incidência: "O impôsto de transmissão supõe, de seu natural, um direito de propriedade que se transfere de uma para outra pessoa e, aliás, a própria denominação o indica na locução inter vivos - vale dizer, um que aliena e outro que adquire" (cf. CASTro Nunes, Problemas da Partilha Tributária, in Revista de Direito Administrativo, vol. I, p. 10).

A prova de que o legislador constituinte quis cingir-se a essa hipótese e evitar variações que importassem em deformação, alteração ou distorção do fato gerador assim definido é que, não obstante as discussões anteriormente existentes, quando quis contemplar a incidência sôbre uma situação que jurìdicamente não se conceitua como de transmissão de propriedade, embora economicamente equivalente, o diploma constitucional the fêz expressa alusão: é o caso da incorporação de propriedade imobiliária ao capital das sociedades, referido na parte final do inciso III do art. 19 da Constituição.

Por outro lado, confirmando a asserção de que só se pode configurar o fato gerador do impôsto de transmissão, em direito constitucional positivo pátrio, quando a hipótese de incidência coincida com uma forma jurídica ("juristische Gestaltungsform") de transmissão ou transferência de propriedade, aí está a pacífica, invariável e torrencial jurisprudência dos nossos tribunais, inclusive da nossa mais alta Côrte de Justiça, a afirmar que é inconstitucional a incidência sôbre promessas de venda de imóveis e suas cessões porque, embora a realidade econômica ou a intentio facti subjacente em tais atos ("wirtschaftliche Betrachtungsweise") possa ensejar efeitos, econômicos já se vê, equivalentes ao da transmissão imobiliária, a forma jurídica não é de transferência de domínio.

Ainda dentro do campo do direito constitucional positivo há uma nova ordem de considerações que não pode ser omitida: é que o constituinte atribui privativamente à União a competência para criar impostos sôbre atos e instrumentos regulados por lei federal (art. 15, VI), excluindo, todavia, tal competência (caso de imunidade por exclusão da competência) quando o ato ou instrumento estiver compreendido dentro da competência privativa estadual ou municipal ( $\$ 50^{\circ}$ do art. 15 ).

Resulta daí um princípio de particular relevância jurídica: é que tal competência impositiva da União é ampla e absorvente, quando se trate de atos e instrumentos regulados por lei federal e so poderá ser excluída quando o ato ou instrumento fôr expressamente atribuído à competência impositiva dos Estados e Municípios.

Por outras palavras, a regra é essa: a competência para tributar atos e instrumentcs regulados por lei federal é, em princípio e normalmente, da União; excepcionalmente, tal competência passará a ser dos Estados e Muni- 
cípios, quando o ato ou instrumento especificamente forem contemplados pela constituição como pressupostos da incidência de impostos destas entidades federadas.

Por conseguinte, verifica-se que, em face da sistemática adotada pela constituição, no que respeita a atos e instrumentos regulados por lei federal, a regra é a competência da União e a exceção a competência dos Estados e Municípios. Consequientemente, por isso mesmo que esta última é excepcional, os dispositivos contidos na discriminação constitucional de rendas hão de ser objeto de interpretação estrita, tôda vez que esteja em cogitação decidir-se pela competência legislativa estadual ou municipal tendo por pressuposto a criação de impostos sôbre atos e instrumentos da espécie dos mencionados. blema:

Chega-se, assim, a uma primeira conclusão parcial a respeito do pro-

a) só se configurará a competência estadual (inclusive do Distrito Federal) para crar e cobrar impôsto sôbre transmissão de propriedade imobiliária inter vivos, quando a hipótese de incidência coincida com um ato jurídico de transmissão de propriedade, como tal definido pelo ordenamento jurídico vigente;

b) quando se trate de qualquer ato ou instrumento, "regulado por lei federal" e que não esteja jurìdicamente definido como de transferência de domínio, a competência impositiva pertencerá privativamente à União.

6. Dentro dêsse quadro geral, cumpre analisar o sistema adotado pela lei específica que, no Distrito Fecieral, regula a incidência do impôsto em causa (Decreto-lei n. ${ }^{\circ}$ 9.626, de 22 de agôsto de 1946).

Decidindo sôbre a incidência, o art. $1 .^{\circ}$ do diploma referido assim determina o fato gerador do impôsto:

"Art. $10^{\circ}-\mathrm{O}$ impôsto de transmissão de propriedade inter vivos inc de sôbre a transferência de bens imóveis por sua natureza ou por disposição legal, quando situações no Distrito Federal, a título oneroso ou gratuito, e em virtude de fatos ou atos jurídicos passados ou praticados inter vivos".

Como se vê, o fato gerador do impôsto está suficientemente definido como sendo aquêle que se conceitua como de transferência de bens imóveis.

Verifica-se, assim, que também em face da lei específica é necessário que haja transferência ou transmissão de domínio para que o impôsto seja devido.

E verdade que ao caput do art. $1^{\circ}$ se segue uma enunciação de diferentes hipóteses de incidência, enunciação essa corporificada no parágrafo único do mesmo art. $10^{\circ}$.

Convém observar, como anota A. BERLIRI, que enunciações dessa espécie correspondem à técnica legislativa de esclarecer-se o conceito que esteja mencionado no dispositivo que reger a enumeração e, por isso mesmo, deverá aquela ser entendida como de caráter exemplificativo e interpretativo. 
O caso do parágrafo único é típico: o que o legislador quis foi exemplificar hipóteses que se contêm no conceito de "transferência de bens imóveis". E' verdade que, na indicação de tais casos, arrolou o de cessão de promessa de venda. Excedeu-se no particular e, por essa razão, foi a incidência julgada inconstitucional.

Mas, nas demais hipóteses, trata-se de transferência de propriedade.

A enunciação contida no parágrafo único do art. $1^{\circ}$ é, assim, meramente exemplificativa e interpretativa, não contendo nenhum caráter ou sentido inovador: é como se o legislador, diante de cada inciso do parágrafo único fizesse preceder as palavras - transferência de bens imóveis...

Visto, assim, o sistema da lei, passemos a ocupar-nos do inciso IV do parágrafo único em cogitação.

7. Diz o parágrafo único do art. $10^{\circ}$ citado, em conjugação $\mathrm{ccm}$ o seu inciso IV:

"Parágrafo único - O impôsto é dev:do sôbre:

IV - Transferência de construções existentes em terreno: -haios, ainda que aos proprietários dos terrenos".

Que quer dizer êsse dispositivo? Quer-se, tão sòmente, esclarecer o conceito consagrado no caput do art. $10^{\circ}$ para dizer que também nesse caso de transferência de domínio incide o impôsto.

$\mathrm{Na}$ verdade, não foi para dar tão óbvio esclarecimento que o legislador assim se expressou. O objetivo do preceito foi, de fato, pronunciar-se sôbre uma hipótese de transferência, ou melhor, de aquisição de domínio, qual a que ocorre por acessão, nos casos apontados pelo art. 546 do Código Civil.

É que, segundo o diploma civil, "aquêle que semeia, planta ou edifica em terreno alheio perde, em proveito do proprietário, as sementes, plantas ou construções mas tem direito à indenização". (art. 546 cit.) .

Mais especialmente, o intuito do legislador foi solucionar debate existente a respeito da incidência do impôsto de transmissão no caso de benfeitorias de natureza imobiliária.

Embora longa a transcrição, vale a pena reproduzir as considerações a propósito desenvolvidas por PETRÔNIO BAPTISTA DE ARAUJO em sua excelente monografia:

"III - Cessão ou venda de benfeitorias. Os regulamentos do impôsto de transmissão incluem entre as espécies tributáveis a cessão ou venda de benfeitorias.

Esse têrmo vem empregado em sua acepção jurídica, para designar as obras e despesas feitas na coisa alheia, com o fim de conservá-la, melhorá-la ou simplesmente embelezá-la. Verifica-se, pois, a hipótese quando as benfeitorias de natureza imóvel, objeto da alienação, são acrescidas ao terreno por outrem que não o proprietário.

Os regulamentos estaduais excluem da incidência "a inđenização de benfeitorias feitas pelo proprietário ao locatário". Não se 
trata pròpriamente de isenção, mas de declaração tácita de que a espécie não implica compra e venda imobiliária.

Com efeito, essa exceção provém do Aviso n. ${ }^{\circ} 200$, de 16 de abril de 1869, pelo qual o Ministério de Negócios da Fazenda comunica ao Diretor Geral das Rendas Públicas "não ser devida a sisa de uma transação, mediante a qual os locatários de umas fazendas pertencentes a um espólio foram indenizados do valor das benfeitorias que nas mesmas fizeram, dando-se por findo o arrendamento".

Em conseqüência, essa regra foi incorporada ao parágrafo único do art. 21 do Regulamento n. ${ }^{\circ} 5.581$, de 28 de março de 1874, com expressa remissão de Aviso n. ${ }^{\circ} 200$.

Para maior compreensão de tese em exame, passamos a fazer um breve relato do fato concreto que determinou a expedição daquele Aviso.

O Marquês de ITANHAEM mantinha dois contratos de arrendamento com arrendatários diferentes. Estes, para tirarem proveito do negócio, fizeram várias plantações no imóvel arrendado. Morto o locador, o testamenteiro e inventariante do espólio, por conveniência dos herdeiros, entrou em acôrdo com os arrendatários para a rescisão dos contratos, indenizando-os do valor das plantações ainda existentes no imóvel.

Submetido o caso à apreciação do Contencioso do Tesouro Nacional e da Seção de Fazenda do Conselho de Estado, opinaram êsses órgãos pela inexigibilidade da sisa, com os seguintes fundamentos: a) transferência dos bens ao de cujus, represêntado pelo inventariante, versava sôbre coisa móvel, porque o arrendatário, que não adquire domínio algum na coisa arrendada, só pode transferir o direito pessoal, consistente no resultado de sua indústria e de seu labor; b) não houve, assim, venda de direitos reais, mas transferência do valor dos serviços, de um jus ad rem, mediante a indenização convencionada.

Não nos parece subsistente essa conclusão, mormente na vigência do Código Civil. Em primeiro lugar, as plantações se caracterizam como imóveis, em virtude dos seguintes dispositivos: "Art. 43. São bens imóveis: I . . as árvores e os frutos pendentes..."; "Art. 58. Principal é a coisa que existe sôbre si, abstrata ou concretamente. Acessória, aquela cuja existência supõe a da principal".

Assim, dá por serem legalmente definidas como imóveis, já por serem acessórios do solo, de cuja natureza participam, as benfeitorias de que se trata não podem receber outra classificação senão a imobiliária .

Em segundo lugar, dispõe o art. 547: "Aquêle que semeia, planta ou edifica em terreno alheio, perde, em proveito do proprietário, as sementes, plantas e construçōes, mas tem direito a indenização..."

Comentando êsse dispositivo, SÁ PEREIra qualifica a troca de benfeitorias pelo seu valor correspondente como compra e venda 
compulsória: "O dono das sementeiras e construções dá ao dono do solo coisas, que the não queria dar, e o dono do solo por elas the paga um preço que não queria pagar. A aquisição da coisa alheia, mediante o pagamento em dinheiro do valor dessa coisa, é compra e venda".

SÁ PEREIRA chama à operação compra e venda cómpulsória porque pressupõe o caso mais freqüente, de indenização forçada. No caso que temos sob as nossas vistas, no qual o locatário, espontâneamente, cede a título oneroso as benfeitorias que lhe pertencem, pcdemos chamar-lhe compra e venda consensual.

Não há nenhuma razão de direito que aconselhe a distinção entre a venda de benfeitorias feita ao locador e aquela feita a qualquer outra pessoa.

A dispensa do impôsto de transmissão, em tal caso, figura nos regulamentos estaduais como um resquício histórico, que não tem fundamentação lógica. Constituída a República, os Estados transplantaram para a sua legislação a antiga regra do Decreto n. ${ }^{\circ} 5.581$ e não cuidaram de suprimí-la nas diversas modificações que se sucederam.

Alguns Estados, entretanto, modernizaram a sua legislação, neste particular. Dentre os elementos que nos foi dado compulsar, notamos que Minas e o Distrito Federal procuraram reagir contra a isenção das benfeitorias, transferidas pelo locatário ao proprietário.

Dispõe o inciso VIII do art. $2 .^{\circ}$ do Decreto mineiro n. ${ }^{\circ} 3.529$, de 12 de janeiro de 1951, que está sujeita ao impôsto "a cessão, transferência, aquis:ção ou venda de benfeitorias, inclusive de construção existente em terreno alheio..."

Por sua vez, declara o inciso IV do Decreto-lei n. ${ }^{\circ} 9.626$, de 22 de agôsto de 1946, vigorante no Distrito Federal, que o impôsto é devido sôbre "transferência de construções existentes em terrenos alheios, ainda que aos proprietários dos terrenos" (cf. o impôsto sôbre a transmissão de propriedade, 1954, pp. 124 e segs.)."

Vê-se, pois, que ainda aí, em confirmação do que antes foi dito, o legislador se manifestou sôbre uma hipótese de transferência de domínio ou, pelo menos, de sua aquisição por acessão.

E' verdade que o legislador fala em "transferência... inclusive ao proprietário do terreno", o que deixa subentendido que a transferência também pode ser feita a terceiros, caso em que não entrará em cogitação o problema das benfeitorias e o impôsto será normalmente devido pela normal e efetiva transferência de domínio.

O fato explica-se, no entanto, por consideraçốes de técnıca legisiatıva. E' que, do ponto de vista técn:co, regem a elaboração da lei os princípios da plenitude e da concentração lógica, segundo os quais, ao regular determinado assunto, deve o legislador abordá-lo em tôda a amplitude dos̀ -aspectos por que êle se possa apresentar, de tal forma a não deixar dúvida no espírito 
do intérprete e do aplicador quanto à verdadeira proporção e sentido Jo mens legis.

Por isso é que, ao invés de apenas referir-se à transferência "ao proprietário do terreno", o legislador fiscal, dentro da melhor técnica, ampliou a dição do preceito com o acréscimo daquele - "inclusive", de modo a evitar especuiaçães e dúvidas que pudessem surgir mediante uma errônea invocação do princípio - inclusio unius...

8. Vê-se, assim, que não sonhou o legislador com a possibilidade absurda de cobrar impôsto de transmissão nos contratos de construção de imóveis.

E assim não pensou porque:

a) isso contraria a sistemática da discriminação constitucional de rendas, segundo a qual à União cabe a competência para tributar tais atos jurídicos, coisa aliás que efetivamente ocorre através da incidência do impôsto do sêlo, prevista pelo art. 40 da tabela anexa à Consolidação respectiva;

b) contraria igualmente o sistema da lei específica que adota o conceito inequívoco de "transferência de bens imóve:s" para caracterizar o fato gerador do impôsto e, quando se refere às construçōes, expressamente alude à sua transferência.

Com efeito, o construtor não tem a propriedade da obra. Mais que isso. não é ao menos possuidor, de vez que não dispõe de nenhum dos direitos inerentes ao domínio. A doutrina predominante entende, mesmo, que, por isso que possuidor não é, não pode o construtor invocar o direito de retenção sôbre a obra.

O contrato de construção é uma obrigação pessoal, cujo objeto único é uma prestação de fato.

O construtor se obriga a fazer a construção. A propriedade dessa, em qualquer momento, é do prestatário do serviço contratado.

Não há, pois, transferência de propriedade e, muito menos, transferência de construção.

Conseqüentemente, quer isoladamente considerado o inciso IV do parágrafo único do art. $10^{\circ}$ em comentário, quer encarado êle em conjugação com o caput do art. $1 .^{\circ}$ e em confronto com o sistema do decreto-lei 9.626, a conclusão é que sôbre os contratos de construção não incide o impôsto de transmissão.

Ad absurdum, mesmo que o legislador tivesse introduzido um preceito tributando tais atos jurídicos, em qualquer dos seus aspectos, o impôsto assim criado seria inconstitucional por invasão da competência privativa da União prevista no inciso VI do art. 15, não podendo prosperar, por isso mesmo, nem sob a enunciação larga da competência concorrente.

9. Chega-se dêsse modo ao final do exame da questão suscitada.

A conclusão é no sentido da não incidência do impôsto de transmissão, no caso de contratos de construção passados entre o proprietário do terreno (prestatário do serviço) e o construtor ou os construtores (prestador do serviço). 